\title{
Post-treatment Process of Semi-solid Powder Rolling
}

\author{
Xia Luo ${ }^{1,2} \cdot$ Yun-Zhong Liu ${ }^{1} \cdot$ Bin Wang ${ }^{2}$
}

Received: 11 June 2015/Revised: 19 August 2015/Published online: 12 October 2015

(C) The Chinese Society for Metals and Springer-Verlag Berlin Heidelberg 2015

\begin{abstract}
Semi-solid powder rolling is a strip manufacturing process, which combines powder rolling with semi-solid rolling in one step to prepare high-performance metallic strips. A total of 7050 aluminum alloy strips were prepared by semi-solid powder rolling and then used to study the post-treatment process and evaluate qualities of post-treated strips. Three post-treatment processes involving sintering, pre-sintering — cold deformation-sintering, and hot rolling were used to process the semi-solid powder rolled strips. The results show that both swelling of pores and densification occur during solid-state sintering while microhardness increases. The decrease in density is due to that the swelling of pores has a larger effect on the density change than that of densification. The relative density reaches $92.6 \%$ with the maximum microhardness of $300 \mathrm{HV}$ after "pre-sintering - cold deformation—sintering" process. High microhardness is due to the ultrafine secondary particles uniformly distributed within the grains. The microhardness and relative density of a hot rolled strip are $176 \mathrm{HV}$ and $99 \%$, respectively, and the secondary particles disappear. Occurrence of recrystallization in these three post-treatment processes makes the grains finer.
\end{abstract}

\section{KEY WORDS: Semi-solid powder rolling; Post-treatment; Sintering; Hot rolling; Pore swelling}

\section{Introduction}

Semi-solid powder rolling (SSPR), proposed by the authors, is mainly used to prepare strips with high quality, especially for alloys that have a wide freezing range and low melting point such as aluminum alloy (AA7050, 2124, etc.) [1]. The $7 \mathrm{xxx}$ series aluminum alloys have been widely used in manufacture of aircraft structural wing components free from welding and riveting exhibiting a

Available online at http://link.springer.com/journal/40195

Yun-Zhong Liu

yzhliu@scut.edu.cn

1 National Engineering Research Center of Near-Net-Shape Forming for Metallic Materials, South China University of Technology, Guangzhou 510640, China

2 School of Materials Science and Engineering, Southwest Petroleum University, Sichuan 610500, China good combination between the strength and fracture toughness [2-4]. Therefore, selecting a reasonable process to make the materials achieve a high quality is extremely important. Generally, 7xxx series plate or strip products are usually manufactured by conventional ingot metallurgy (I/ M) process. Subsequently, the materials are further processed (e.g., homogenization, hot rolling, sometimes cold rolling and then heat treatment, etc.) to meet the required properties. Therefore, the procedure is complex and energy wasting. Even though the aluminum alloy strips prepared by semi-solid rolling (such as rheo-rolling), powder rolling and spray rolling attract attention, they result in some defects such as the flaws and pores [5-9]. Then, $\mathrm{Zu}$ and Luo [10] studied semi-solid powder forming (SPF) and $\mathrm{Wu}$ et al. [11-16] discussed various processing routes. Until now, SPF is mainly applied in the extrusion and compaction tests to prepare bulk materials. Hence, 7050 alloy strips prepared by SSPR have shown a promising development. In the early stage of research, semi-solid powder 
rolling shows a promise for reducing strip manufacturing costs and saving energy while improving quality. The inherent rapid solidification, easily controllable process conditions and solid solubility extension may also provide a new choice for the alloy development [1].

As shown in Ref. [1], the relative density of semi-solid powder rolled strip ranges from 87.1 to $96.5 \%$ corresponding liquid of $\sim 65 \%$. When the strip is prepared under a low liquid fraction $(<10 \%)$, a post-treatment technology would be necessary to eliminate the pores and improve the mechanical property of the strips. The present study is to explore an effective and shortest post-treatment technology for achieving good strips and optimizing the main parameters of post-treatment. The mechanisms of the microstructure evolution and its effect on the mechanical property during post-treatment are discussed as well.

\section{Experimental}

A schematic of the approach and the experimental apparatus are shown in Fig. 1. The powders used in this work are the gas atomized 7050 aluminum alloy powders (Al$6.43 \mathrm{Zn}-2.26 \mathrm{Mg}-2.02 \mathrm{Cu}$ ) with a nearly spherical morphology and a mean particle diameter of $75 \mu \mathrm{m}$. The experiments were carried out on a powder rolling machine with rollers preheated to $300{ }^{\circ} \mathrm{C}$, and the rolling temperature is being maintained. The diameter of roller is $150 \mathrm{~mm}$ with a width of $100 \mathrm{~mm}$, a rolling gap of $0.1 \mathrm{~mm}$ and a rotating speed of $0.4 \mathrm{rad} / \mathrm{s}$. The 7050 powders were firstly heated to the semi-solid temperature range with different

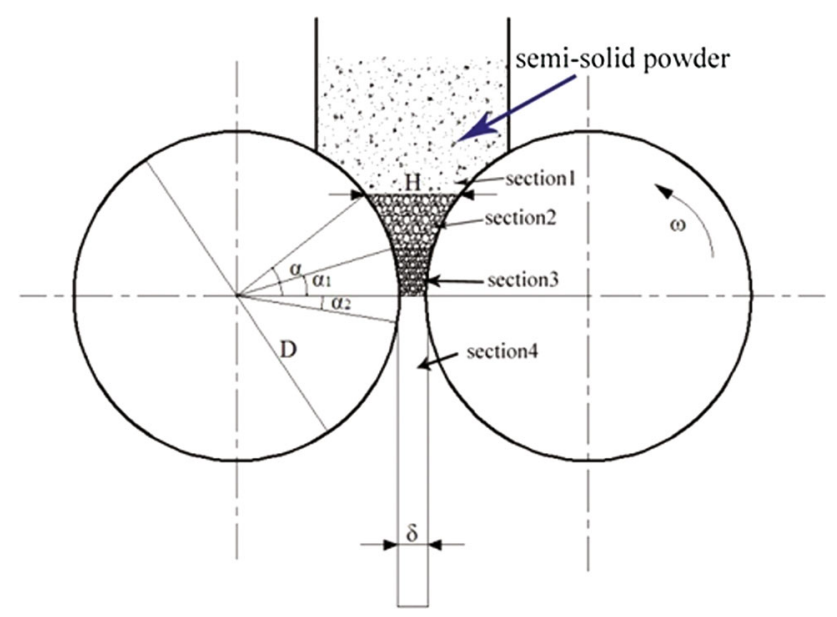

Fig. 1 Schematic of semi-solid powder rolling process [1] holding times. And then the semi-solid powders were fed into the gap. Semi-solid powders were obtained by quenching from the pre-SSPR heating temperature of $555^{\circ} \mathrm{C}$ for $30 \mathrm{~min}$ (as shown in Fig. 2a). The strip (Fig. 2b) with a width of $100 \mathrm{~mm}$ and thickness of about $2 \mathrm{~mm}$ shows a good surface and complete shape.

In order to study the changes between semi-solid powder rolled strips and post-treated strips clearly, the SSPR processed strip with the lowest density was used in this study. So, the gas atomized 7050 aluminum alloy powders were firstly heated at $555^{\circ} \mathrm{C}$ and held for $30 \mathrm{~min}$ in a furnace under $\mathrm{Ar}$ atmosphere (the corresponding liquid fraction is $1.38 \%$ based on microstructural analysis and the actual solidification temperature of 7050 aluminum alloy powder is $524-658{ }^{\circ} \mathrm{C}$ ). Subsequently, the semi-solid powders were fed into the gap and consolidated into strips. The samples were discontinuously selected from the central zone of the strips along the rolling direction and then divided into four groups labeled with A, B, C and D. At last, the samples of the group A were sintered at 474, 492, 510 and $520^{\circ} \mathrm{C}$, respectively, for $2 \mathrm{~h}$. Then, they were quickly water-quenched to room temperature and air-dried. The samples of the group B were sintered at $510{ }^{\circ} \mathrm{C}$ for 1 , 2,3 and $5 \mathrm{~h}$, respectively. Then, they were also quickly water-quenched to room temperature as well as air-dried. The specimens of the group $\mathrm{C}$ were firstly sintered at $510{ }^{\circ} \mathrm{C}$ for $2 \mathrm{~h}$ and water-quenched to the room temperature, and then they were uniaxially compressed in the thickness direction at room temperature. These deformed samples were sintered again at $528{ }^{\circ} \mathrm{C}$ for $2 \mathrm{~h}$ and then furnace cooled to the room temperature. The atmosphere for all the sintering processes is dry hydrogen. The samples of the group D were firstly heated to $471^{\circ} \mathrm{C}$ for $30 \mathrm{~min}$ in the furnace and then single-pass hot rolled with $30 \%$ thickness reduction, and air-cooled to the room temperature. The roller of machine was preheated to $200{ }^{\circ} \mathrm{C}$ in order to retain the rolling temperature at $471{ }^{\circ} \mathrm{C}$. Finally, the relative densities of all the samples were tested. Microstructure observation was carried out with LcicaDMI500M after etching with the Keller's reagent. The phase identification was carried out by X-ray diffraction (XRD) analysis using D8 ADVANCE (Bruker, Germany) $\mathrm{Cu}\left(K_{\alpha 1}+K_{\alpha 2}\right)$ (the diffraction angle $2 \theta$ is $10^{\circ}-90^{\circ}$, scan speed is $17.7 \mathrm{~s} / \mathrm{step})$. The microhardness was tested by HVs-100 Vickers with the loading force of 0.98 N. SEM observation was carried out by NovaNanoSEM430 for identifying the morphology and distribution of second phase particles. The pore size was measured from SEM pictures taken from a polished plane, using the line-intercept method, taking account of at least 10 pores. 


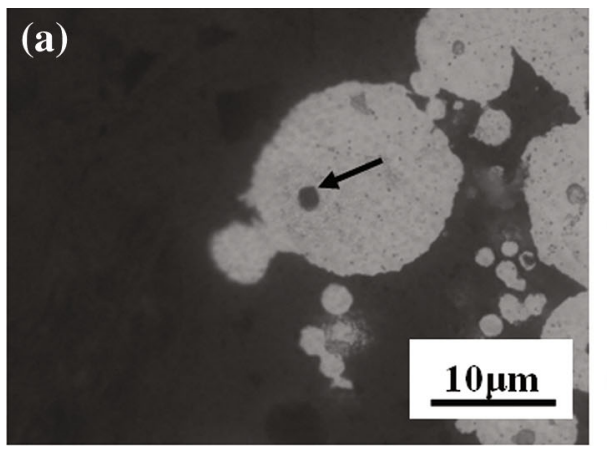

(b)

Fig. 2 Microstructure of semi-solid powder a, a strip prepared by semi-solid powder rolling b [1]. Arrow indicates the liquid phase

\section{Results and Discussion}

\subsection{Sintering of Semi-solid Powder Rolled Strips}

\subsubsection{Effect of Sintering Temperature on the Microstructure}

Figure 3 shows the microstructures of the semi-solid powder rolled strip at different locations. The microstructure of the strip is characterized by a randomly distributed rosette structure with isolated and open pores and some deformed or broken particles. Some particle boundaries and pores can be observed clearly. The microstructure on the surface in Fig. 3a consists of more pores compared with that located in the mid-thickness. It may be due to that the temperature on the surface decreases rapidly, leading to a poor interfacial bonding. The relative density and the microhardness of strip are $87.1 \%$ and $92.3 \mathrm{HV}$, respectively. Liu et al. [1] discussed the influence of liquid fraction on the microstructure and density of the SSPR processed strip and showed that too little liquid cannot completely fill in the pores and gaps, therefore, leading to a poor microstructure and low density.

Figure $4 \mathrm{a}, \mathrm{b}$ represents the microstructures of the sintered strips for $2 \mathrm{~h}$ at 474 and $492{ }^{\circ} \mathrm{C}$, respectively. Some prior particle boundaries still exist and large pores can be observed. Those boundaries that closely contact with each other start to become thin and then disappear (Fig. 4a). Microstructure from the sample sintered at $492{ }^{\circ} \mathrm{C}$ shows that parts of the prior particle boundaries disappear and the metallurgical bonds between particle boundaries occur (Fig. 4b). However, Fig. 5 indicates that the corresponding relative densities of the specimens sintered at $474-492{ }^{\circ} \mathrm{C}$ decrease to about $83 \%$. Additionally, not only has the density fallen above, by growth of the pores, but the rosette structure of dark etching second phase has broken up to isolated particles at $474{ }^{\circ} \mathrm{C}$ and these have extensively coarsened at $492{ }^{\circ} \mathrm{C}$ before becoming largely dissolved up at the higher temperatures. This is due to that the solubility of the copper, magnesium and zinc rich particle rises with temperature [17]. When the sintering temperature increases to $510{ }^{\circ} \mathrm{C}$, all the prior particle boundaries disappear and some new fine grains $(\sim 10 \mu \mathrm{m})$ are observed. When the semi-solid powder rolled strip is sintered at $520^{\circ} \mathrm{C}$, the grains become finer and microhardness increases. However, the relative density of the specimens sintered at $510-520{ }^{\circ} \mathrm{C}$ also decreases with a smaller change.

\subsubsection{Effect of Holding Time on the Microstructure}

Figure 6 shows the microstructures of the strips sintered at $510{ }^{\circ} \mathrm{C}$ at different times. Some of the prior particle boundaries do not disappear or the metallic bonding between particles does not occur when sintered for $1 \mathrm{~h}$ (Fig. 6a). When the strip is sintered for $2 \mathrm{~h}$, all of the prior particle boundaries are replaced by clear simple grain boundaries (Fig. 6b). Figure 7 indicates that the specimen sintered for $2 \mathrm{~h}$ has the highest microhardness and a relative density of about $86 \%$. But, when the sintering time is longer than $2 \mathrm{~h}$, the grain size increases and the microhardness of the strips decreases rapidly with an increasing sintering time (Figs. 6c, d, 7). The relative density decreases to $81.9 \%$ when the sintering time is $5 \mathrm{~h}$. Hence, sintering time influences the microstructure and microhardness greatly and the best sintering time is $2 \mathrm{~h}$.

In solid-state sintering, raising sintering temperature helps the metallurgical bonding occur while prolonging sintering time causes serious grain growth. Based on the former results, all the densities of the specimens fall with the microhardness increase to a certain extent after sintered at $474-520{ }^{\circ} \mathrm{C}$. What is more surprising is that these grains/ prior particles are still largely isotropic and not flattened after sintering. However, Fig. 3 shows a microstructure with many deformed particles/grains. Additionally, the clear reduction in the grain size can be seen after sintering at $510{ }^{\circ} \mathrm{C}$ and more clearly at $520{ }^{\circ} \mathrm{C}$. Hence, recrystallization of deformed grains/prior particles must take place during sintering. As shown in Figs. 3, 4 and 6, the initial 

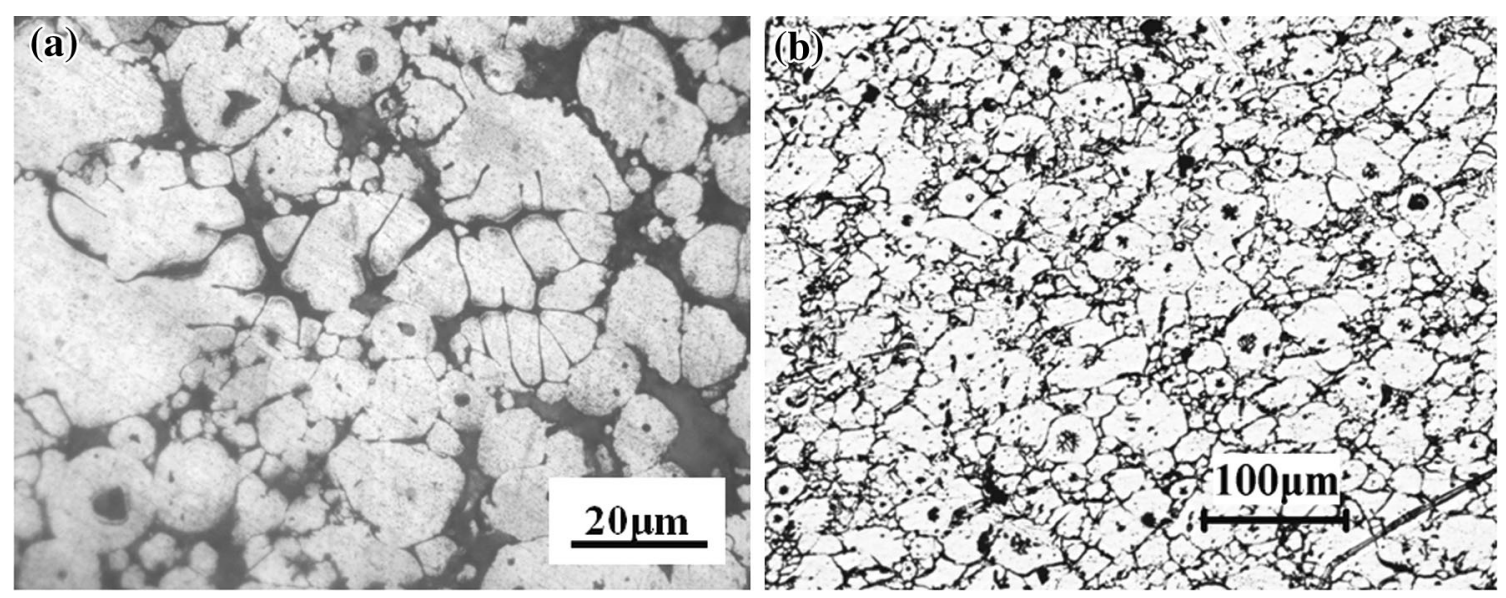

Fig. 3 Microstructures of the semi-solid powder rolled strip prepared under $555^{\circ} \mathrm{C} / 30$ min at different locations: a the surface [1], b midthickness

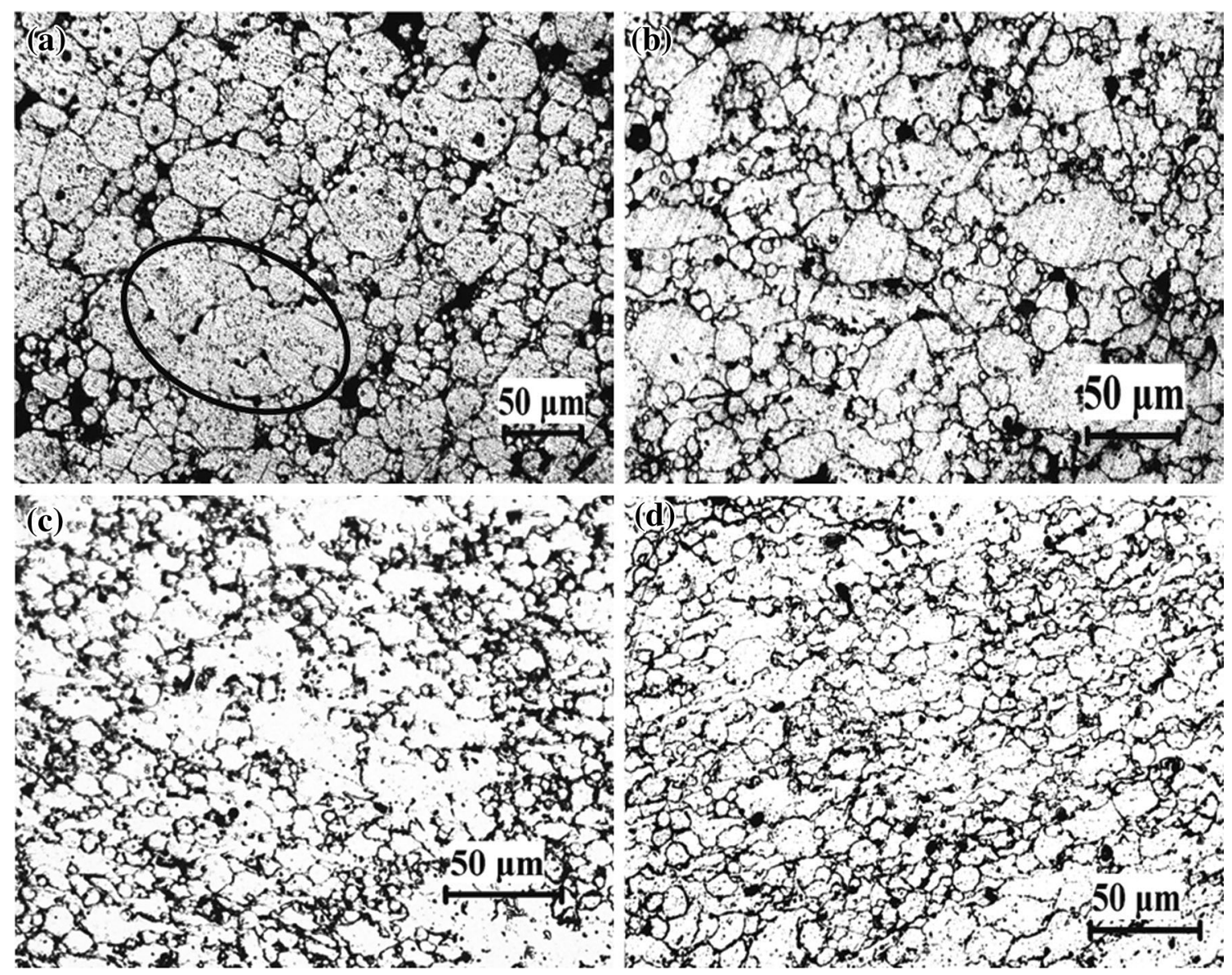

Fig. 4 Microstructures of the post-treated strip sintered at different temperatures for $2 \mathrm{~h}$ under $\mathrm{H}_{2}$ atmosphere: $474{ }^{\circ} \mathrm{C} \mathrm{a}, 492{ }^{\circ} \mathrm{C}$ b, $510{ }^{\circ} \mathrm{C} \mathbf{c}$, $520{ }^{\circ} \mathrm{C} \mathrm{d}$

grain size is related to the prior particle size (most particles usually solidify to a single grain) and this is then reduced by deformation-induced recrystallization to a fine grain size. The recrystallization is incomplete at $510{ }^{\circ} \mathrm{C}$ but is essentially complete by $520^{\circ} \mathrm{C}$. It is generally known that the driving force for recrystallization is provided by the stored energy of deformation [18, 19]. Additionally, onset of recrystallization though helped by the increase in 


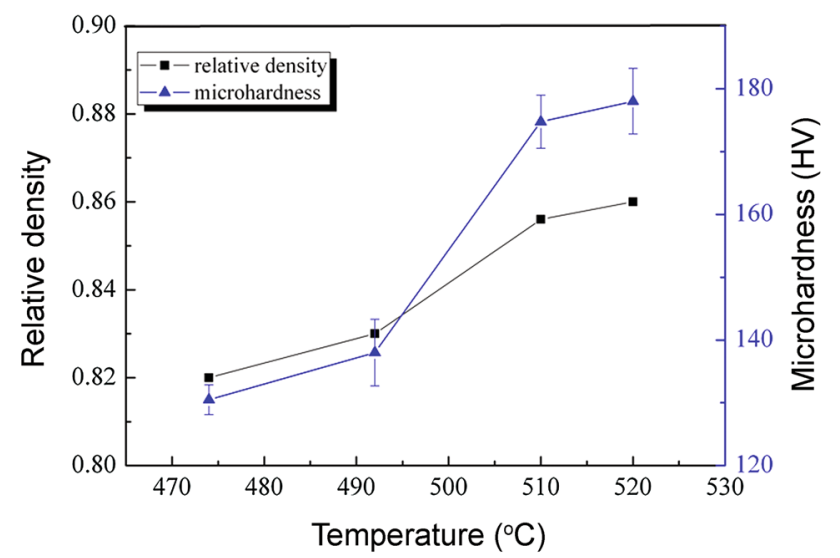

Fig. 5 Relative density and microhardness of strips after sintering for $2 \mathrm{~h}$ at different temperatures

thermal energy at higher temperature is also clearly going to be helped by the dissolution, and at higher temperatures, the second phase particles can pin migration grain boundaries [20]. The loss of the particles at higher temperature is clearly visible in Fig. 4b, c. High temperature provides a higher mobility of atoms that allow recrystallization to occur. Then as the sintering temperature increases, recrystallization occurred completely leading to a considerable refinement of the original structure (more ultra-fine recrystallized grains form).

Another surprising result is the decreased density for the sintered specimens. Figure 8 shows the porosities of a SSPR processed strip and sintered strips, respectively. It can be seen that the pores grow larger and the average pore size increases after sintering, which leads to the decrease in the density. The increase in pore size may be likely that gas/air can be easily trapped in the strips because the rolling procedure of SSPR was carried out in Ar atmosphere and then the trapped gas will cause swelling of pores during sintering. Small pores grow by a combination of internal gas pressure and pores coalescence. The internal pressure $\left(P_{\text {in }}\right)$ of the pores with entrapped gas is determined by: $P_{i n}=P_{e x i}+\frac{2 \gamma}{r_{p}}[21,22]$, where $\gamma$ is the interfacial energy, $r_{\mathrm{p}}$ is the pore radius, $P_{\text {exi }}$ is the gas pressure of atmosphere, equals to $1.01325 \times 10^{5} \mathrm{~Pa}$. $P_{\text {out }}$ equals to $P_{\text {exi }}$ and so $P_{\text {in }}=2 \gamma / r_{\mathrm{p}}$. In order to calculate the pore radius during sintering, the following assumption should be made: The gas is regarded as ideal gas and follows the ideal gas

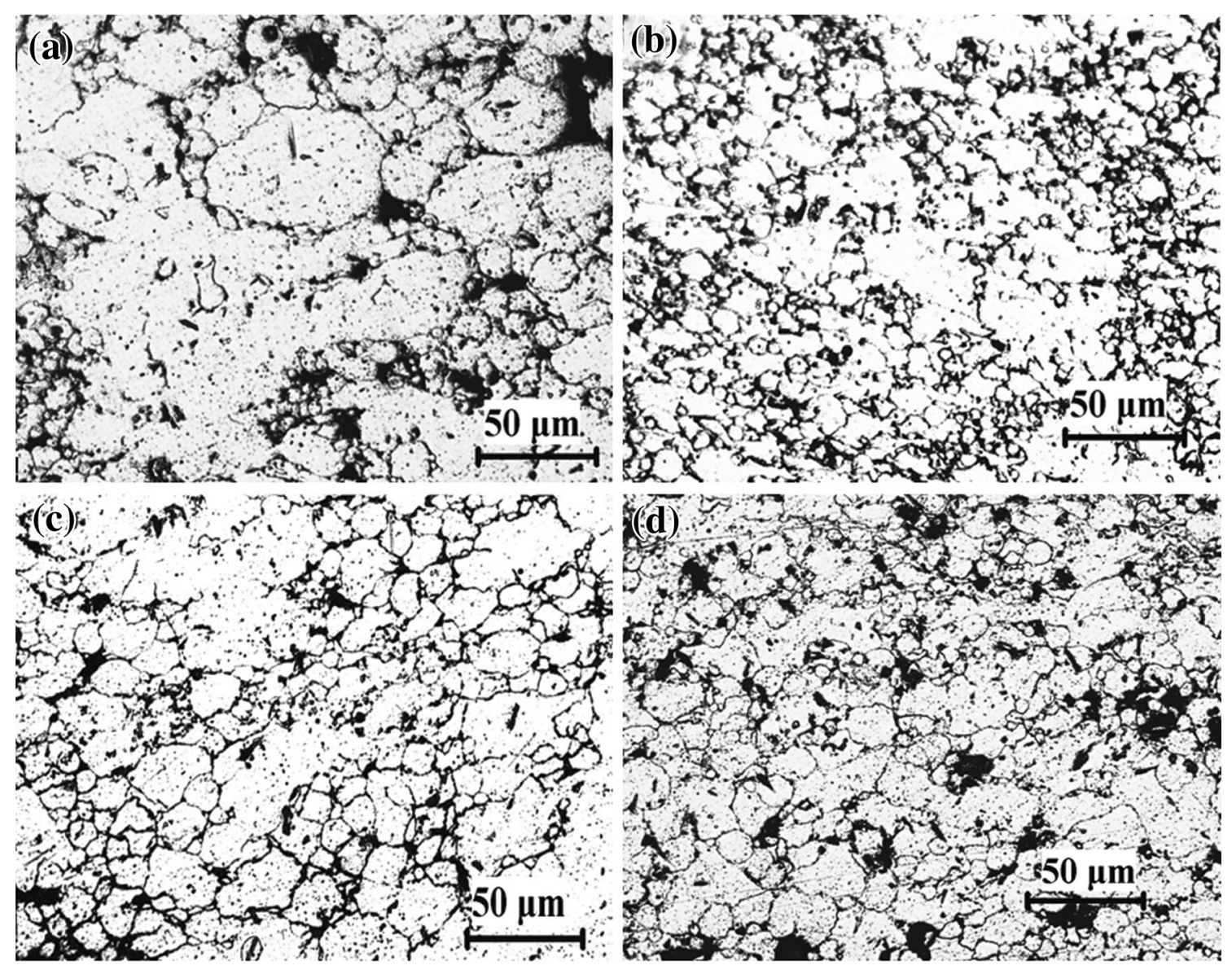

Fig. 6 Microstructures of strips sintered at $510{ }^{\circ} \mathrm{C}$ for different times in $\mathrm{H}_{2}$ atmosphere: $1 \mathrm{~h}$ a, $2 \mathrm{~h} \mathrm{~b}, 3 \mathrm{~h}$ c, $5 \mathrm{~h}$ d 


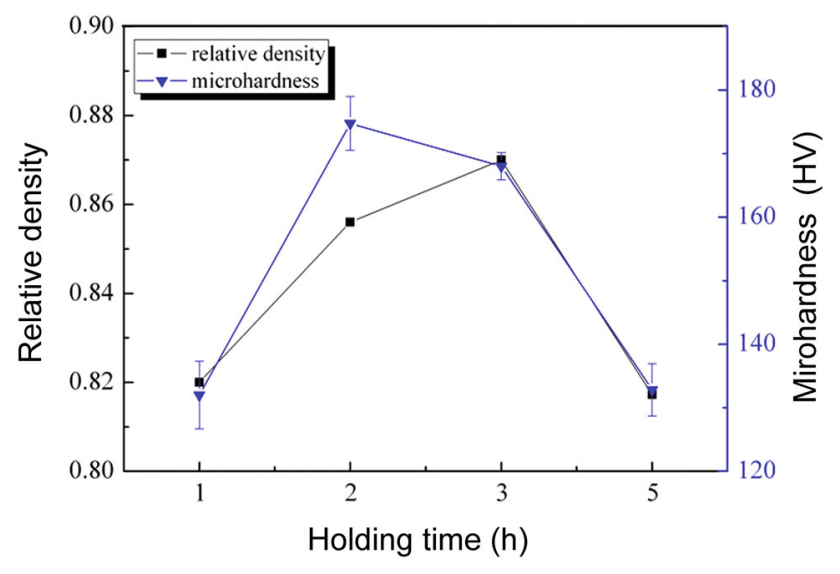

Fig. 7 Relative density and microhardness of strips sintered at $510{ }^{\circ} \mathrm{C}$ for different times

equation, and so $\frac{r_{p 1}}{r_{p 2}}=\sqrt[3]{\frac{T_{1}}{T_{2}}}$ can be obtained, where $r_{\mathrm{p} 1}$ is the initial pore radius, $r_{\mathrm{p} 2}$ is the pore radius after sintering, $T_{1}$ is the initial temperature and $T_{2}$ is the sintered temperature. Figure 8 shows that the measured pore diameter of semisolid powder rolled strip is $6.08 \mu \mathrm{m}$ and it increases to $14.42 \mu \mathrm{m}$ after sintering. The calculated pore diameter after being sintered at $474{ }^{\circ} \mathrm{C}$ is $16.23 \mu \mathrm{m}$, which is a little higher than the measured results. And the pore diameter in cold rolled strip is $2.85 \mu \mathrm{m}$, while it increases to $4.9 \mu \mathrm{m}$ after being re-sintered at $528{ }^{\circ} \mathrm{C}$. The corresponding calculated pore diameter after re-sintering is $7.88 \mu \mathrm{m}$. Based on these results, it can be concluded that the calculated results are higher than the measured results. It may be due to that the densification will make the pores shrink to some degree. Thus, as the temperature increases, pore coarsening gives a greater overall pore volume and specimen swelling. When the pore coalescence occurs, the density is reduced because of pore expansion. Such kind of phenomena was also found in Ref. [22, 23]. With longer sintering time in hydrogen, pores and grains seriously grow. Pan et al. [24] stated that when grain growth is prohibited, a large pore shrinks by a neighbor-switching mechanism similar to the superplastic deformation. Therefore, it is the even counter productive to promote grain growth in order to eliminate large pores. By analyzing the density change and microstructures of the sintered specimens, it can be concluded that both swelling of the pores and densification occur. The sintered density decreases to the least extent (decrease by $1.2 \%$ ) when densification occurs to the maximum degree. Seen from this, the density decrease resulting from swelling of the pores is higher than density increase resulting from densification. It has been widely recognized that the presence of the surface oxide makes aluminum difficult to sinter [25]. The oxide prevents solid-state sintering in low melting point metals [26, 27]. This has been explained in terms of the relative diffusion rates through the oxide and the metal, for metals with stable oxides [2830]. Ref. [1] has shown the effect of oxides on the combination mechanisms. Those surface oxide layers that not broken down will impede the diffusion of atoms and, therefore, prevent densification.

\subsection{Pre-sintering—Cold Deformation—Sintering}

Figure 9 represents the microstructures of the specimens pre-sintered for $2 \mathrm{~h}$ at $510{ }^{\circ} \mathrm{C}$ and then cold compression. The microstructures were obtained without etching in order to observe the pores change. It can be seen that pores (the black spots are pores) are remarkably elongated and even more collapsed in the flow direction of the material and the relative density increases with increasing deformation extent (their relative densities are 93.2, 94 and 95.4\%, respectively). Figure 10 shows the microstructures of presintered samples with different cold deformation extents $(0$, 30,50 and $60 \%$, respectively) after being re-sintered at $528{ }^{\circ} \mathrm{C}$ for $2 \mathrm{~h}$ under $\mathrm{H}_{2}$ atmosphere. Figure 11 shows that the relative density of the pre-sintered sample then re-sintered for $2 \mathrm{~h}$ at $528{ }^{\circ} \mathrm{C}$ decreases to $82 \%$, which is close to that of the sample sintered for $5 \mathrm{~h}$ at $510{ }^{\circ} \mathrm{C}(81.9 \%)$. Figure 10a also shows that some isolated pores can be observed. Seen from semi-solid powder rolled strip and sintered strips, the density decreases by $5.9 \%$ to the maximum extent. It is obvious that the relative density of the samples after re-sintering (about 92\%) decreases again compared with the samples before re-sintering. Moreover, the pore size increases slightly after re-sintering (as shown in Fig. 8). This indicates the trapped gas swelling of pores.

Under the same sintering temperature and sintering time, as the deformation extent increases, the relative density and microhardness increase. When the deformation extent is $30 \%$, a little of prior particle boundaries can be seen while large pores disappear completely (Fig. 10b). Generation of new, recrystallized grains $\sim 10 \mu \mathrm{m}$ in size occurs on the boundaries of the original grains as well as the prior particle boundaries. When the deformation extent increases to $50 \%$, the grains are elongated slightly in the direction of materials flow and many secondary phase particles dispersed within the grains (as shown in Figs. 10c, 12). As the cold deformation extent reaches to $60 \%$, the size and shape of recrystallized grains remain constant while the second phase particles precipitate more. More deformation degree leads to a large rise in the recrystallized region. Additionally, further deformation leads to a greater elongation of original grains/particles and these grains/particles are oriented perpendicularly to the compression axis (Fig. 10d). Figure 11 shows the relative density and microhardness of strips treated with different 

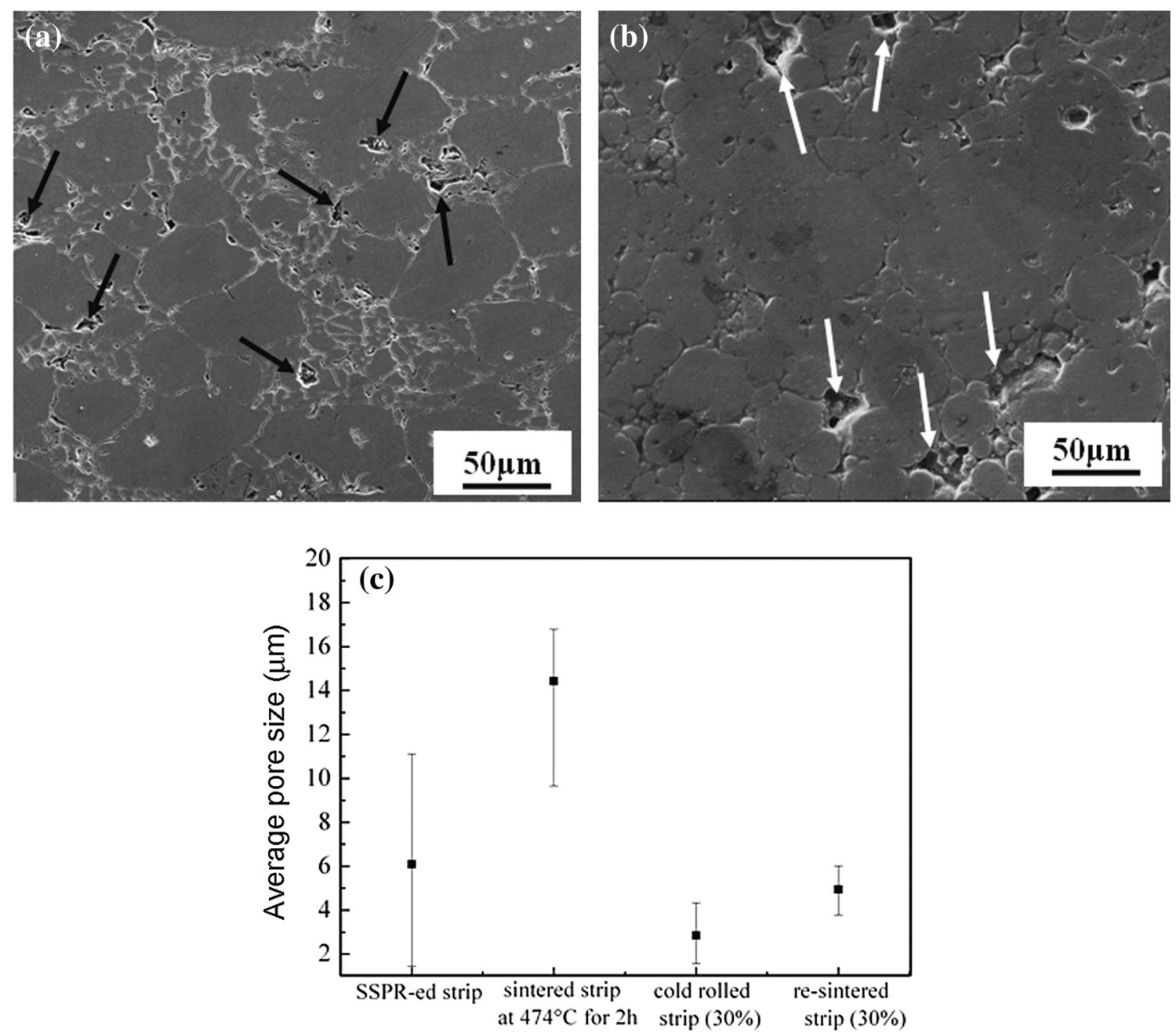

Fig. 8 SEM of SSPR processed strips a, strips sintered at $474^{\circ} \mathrm{C}$ for $2 \mathrm{~h} \mathrm{~b}$, the average pore size under different conditions c. Arrows indicate the pores
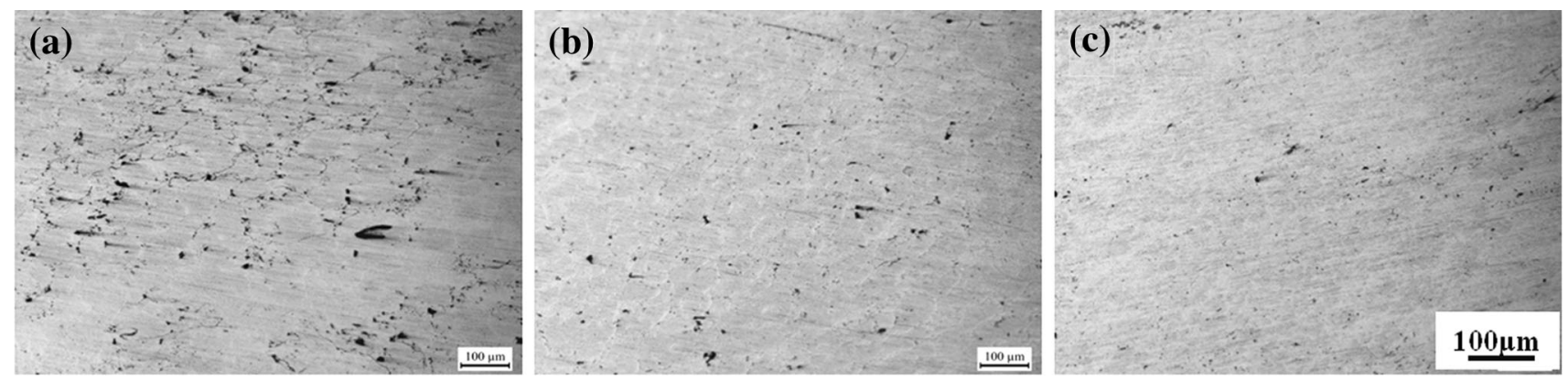

Fig. 9 Porosity of the samples pre-sintered for $2 \mathrm{~h}$ at $510{ }^{\circ} \mathrm{C}$ and then cold compressed $30 \%$ a, $50 \%$ b, $60 \%$ c

deformation extents (30, 50 and 60\%, respectively). It can be seen that the relative density increases steadily with increasing deformation extent, while the microhardness increases dramatically. The turning point of microhardness is that the deformation extent is $30 \%$. It is related to the uniformly dispersed secondary particles because these particles can improve the microhardness. Figure 12 shows the SEM of the strips sintered at $528{ }^{\circ} \mathrm{C}$ for $2 \mathrm{~h}$ after being deformed. XRD in Fig. 13 indicates that deformed samples after re-sintering are composed of $\alpha(\mathrm{Al})$ and secondary particles of $\mathrm{MgZn}_{2}$ and $\mathrm{CuMgAl}_{2}$. Therefore, the microhardness of the sample is improved remarkably. As shown 


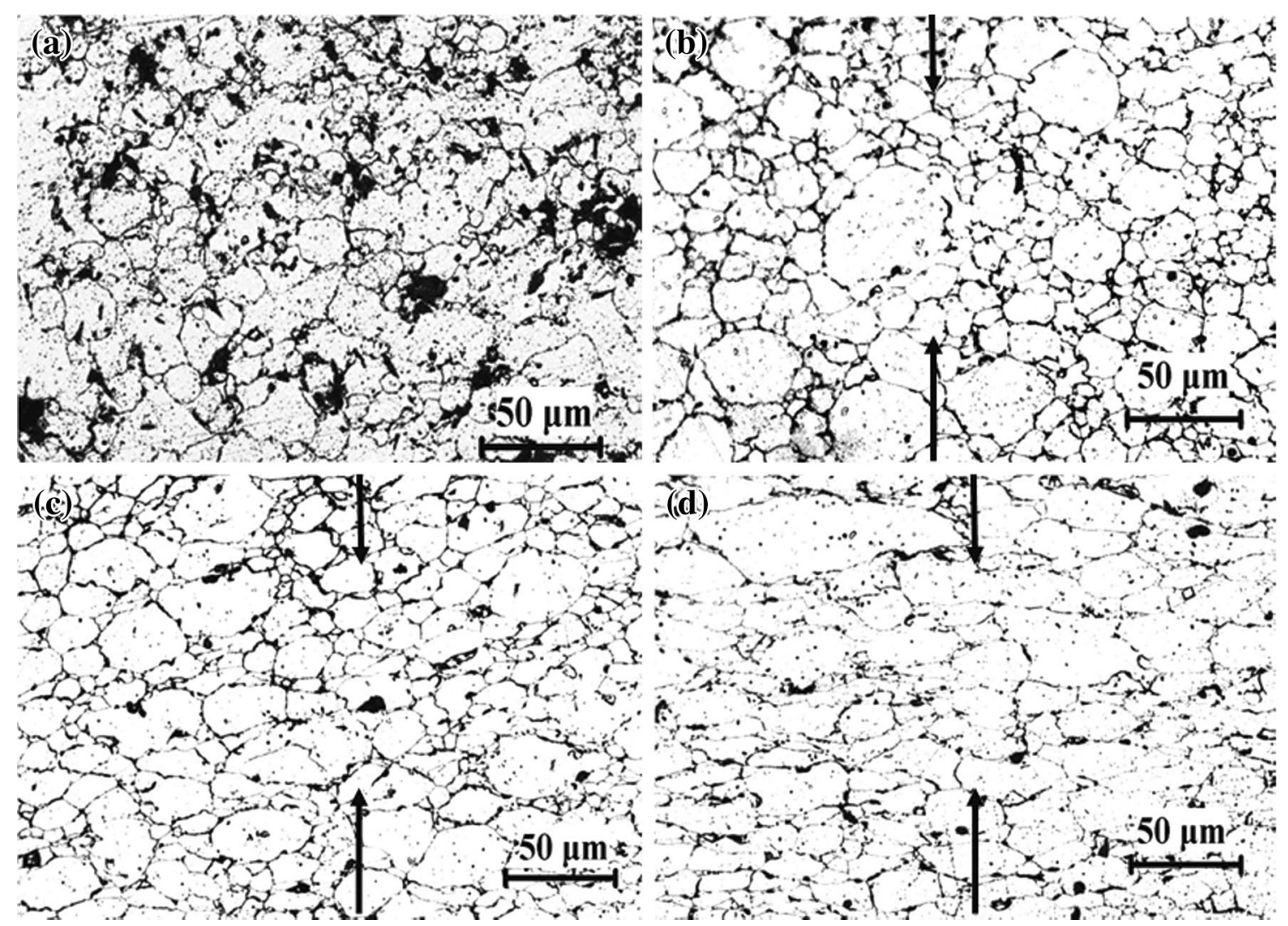

Fig. 10 Microstructures of the samples pre-sintered for $2 \mathrm{~h}$ at $510{ }^{\circ} \mathrm{C}$, then cold compressed $0 \%$ a, $30 \%$ b, $50 \%$ c, $60 \%$ d and then re-sintered at $528^{\circ} \mathrm{C}$ for $2 \mathrm{~h}$. Arrows indicate the deformation axis

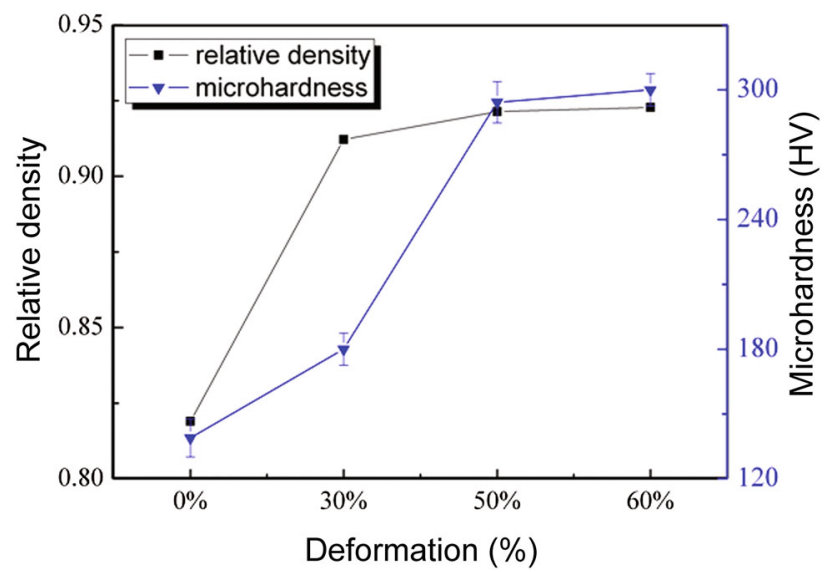

Fig. 11 Relative density and microhardness of the samples presintered for $2 \mathrm{~h}$ at $510{ }^{\circ} \mathrm{C}$, then cold compressed $0 \%$ a, $30 \%$ b, $50 \%$ c, $60 \% \mathrm{~d}$ and then re-sintered at $528{ }^{\circ} \mathrm{C}$ for $2 \mathrm{~h}$

in Fig. 11, the maximum microhardness of the "pre-sintering-cold deformation-sintering" treated strips increases by $52.3 \%(300 \mathrm{HV})$ and density increases as well compared with the samples pre-sintered. It may be due to the following two reasons: On the one hand, deformation is required to make oxide layers break down further and eliminate pores. And then diffusion of atoms occurs easily in the following sintering process. On the other hand, Vlach et al. [31] discussed that cold deformation accelerates the precipitation of the secondary particles and this precipitation is dependent on deformation degree. As deformation degree increases more nano-scaled secondary particles in the grain interiors precipitate during re-sintering. This is also proved by the authors' another article.

In short, "pre-sintering-cold deformation-sintering" can improve the relative density and microhardness remarkably although its procedure is too long and energy wasting. In this kind of post-treatment process, cold deformation before re-sintering effectively interrupts the oxides and eliminates pores and makes the strip store more deformation energy for the following re-sintering process. It provides perfect conditions for recrystallization, diffusion and precipitation of secondary particles during the following sintering. Therefore, they occur completely and easily among the interparticle boundaries and then semisolid powder rolled strip becomes dense. 

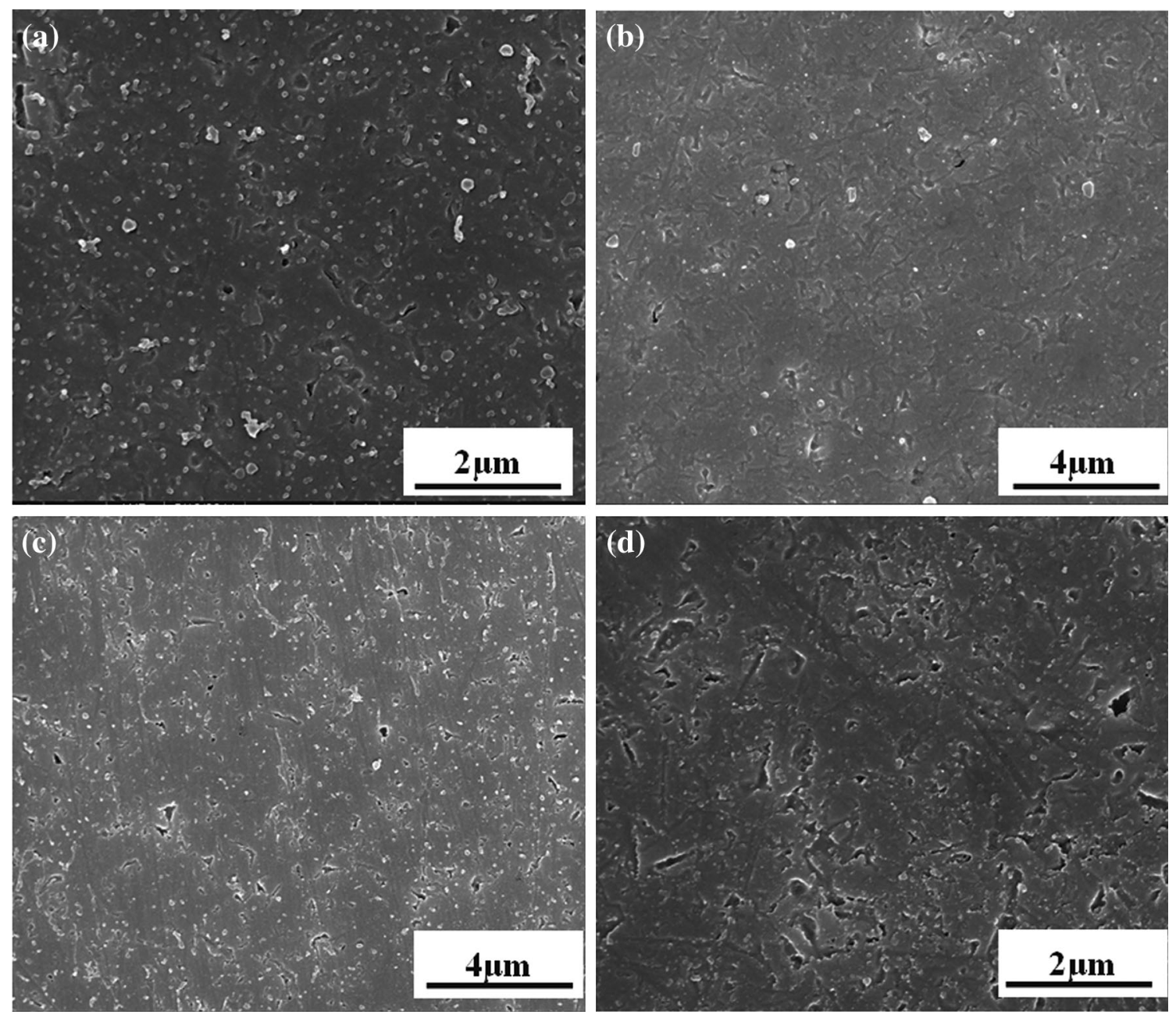

Fig. 12 SEM of the samples pre-sintered for $2 \mathrm{~h}$ at $510{ }^{\circ} \mathrm{C}$, then cold compressed $60 \% \mathbf{a}, 50 \% \mathbf{b}, 30 \% \mathbf{c}, 0 \%$ d and then re-sintered at $528{ }^{\circ} \mathrm{C}$ for $2 \mathrm{~h}$

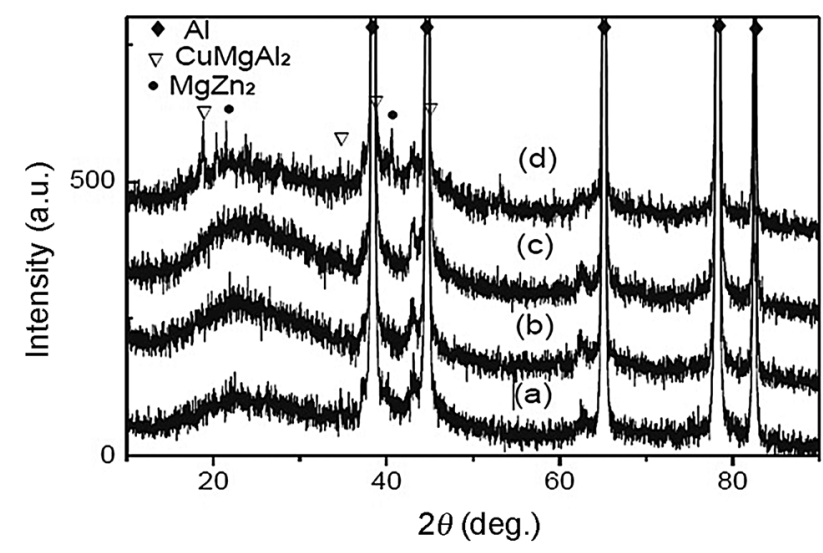

Fig. 13 XRD patterns of the samples pre-sintered for $2 \mathrm{~h}$ at $510{ }^{\circ} \mathrm{C}$, then cold compressed $0 \%$ a, $30 \%$ b, $50 \%$ c, $60 \%$ d and then resintered at $528^{\circ} \mathrm{C}$ for $2 \mathrm{~h}$

\subsection{Hot Rolling of the Semi-solid Powder Rolled Strips}

Liu et al. [1] have discussed the microstructure evolution and mechanical property of the semi-solid powder rolled strips after hot rolling. In this study, the changes between the hot rolled strips and the semi-solid powder rolled strips were analyzed in detail. Additionally, here emphasis is on the differences between post-treated strips. Figure 14a shows the microstructure and Fig. 14b is SEM image of the strips after single-pass hot rolling with $30 \%$ thickness reduction. The microstructure after hot rolling consists of fine grains $(\sim 43 \mu \mathrm{m})$, and the particle size was reduced by dynamic recrystallization to a fine grain size. The pores presented in the semi-solid powder rolled strip disappear after hot rolling. The relative density and the microhardness of the hot rolled strips are $99.9 \%$ and $176 \mathrm{HV}$, respectively. It is seen from Fig. $14 \mathrm{a}, \mathrm{b}$ that the dynamic 
recrystallization is incomplete in some regions because there are still a few of elongated particles/grains. And in some areas, the recrystallization occurs partially, which means that recrystallization occurs largely but incompletely during hot rolling.

Figure $14 \mathrm{c}$ shows that the diffraction peaks of secondary phase particles such as $\mathrm{MgZn}_{2}$ can be observed in the semisolid powder rolled strip, which is the same as that observed by Liu et al. [1]. The microstructure and XRD results show that the second phase particles disappear completely after hot rolling. Hence, the microhardness of the hot rolled strip is relatively low compared with the presintering - cold deformation - sintered strip, due to that the secondary phase particles were dissolved into the matrix when heated at $471{ }^{\circ} \mathrm{C}$ for $30 \mathrm{~min}$. Rapid air cooling makes much of the magnesium, zinc and copper be retained in the matrix, therefore, leading to form supersaturated solid solution [17]. Then it is too late to precipitate secondary phase particles during hot rolling. In short, the following hot rolling is helpful for improving the mechanical properties of the semisolid rolled strips.

It was demonstrated that nearly complete densification during hot rolling occurs through various stages. With a low liquid fraction $(<10 \%)$, the main mechanism of hot densification can be divided into three stages proposed by Vajpai and Dube [32]. In the first stage, the deformation degree is mainly used to reduce thickness and eliminate pores. At the final stage, the plastic deformation of the strips stores deformation energy, thereby leading to dynamical recrystallization. Therefore, it seems that the final stage of densification mechanism with low liquid fractions is the same as that of dense strips. And the semisolid powder rolled strip prepared with low liquid becomes a dense strip mainly via hot densification rolling while the dynamic recrystallization plays a role of refining grains.

A very striking result was found that the relative density of the hot rolled strips then re-sintered at $528{ }^{\circ} \mathrm{C}$ for $2 \mathrm{~h}$ under $\mathrm{H}_{2}$ atmosphere decreases to $96.9 \%$. It is well

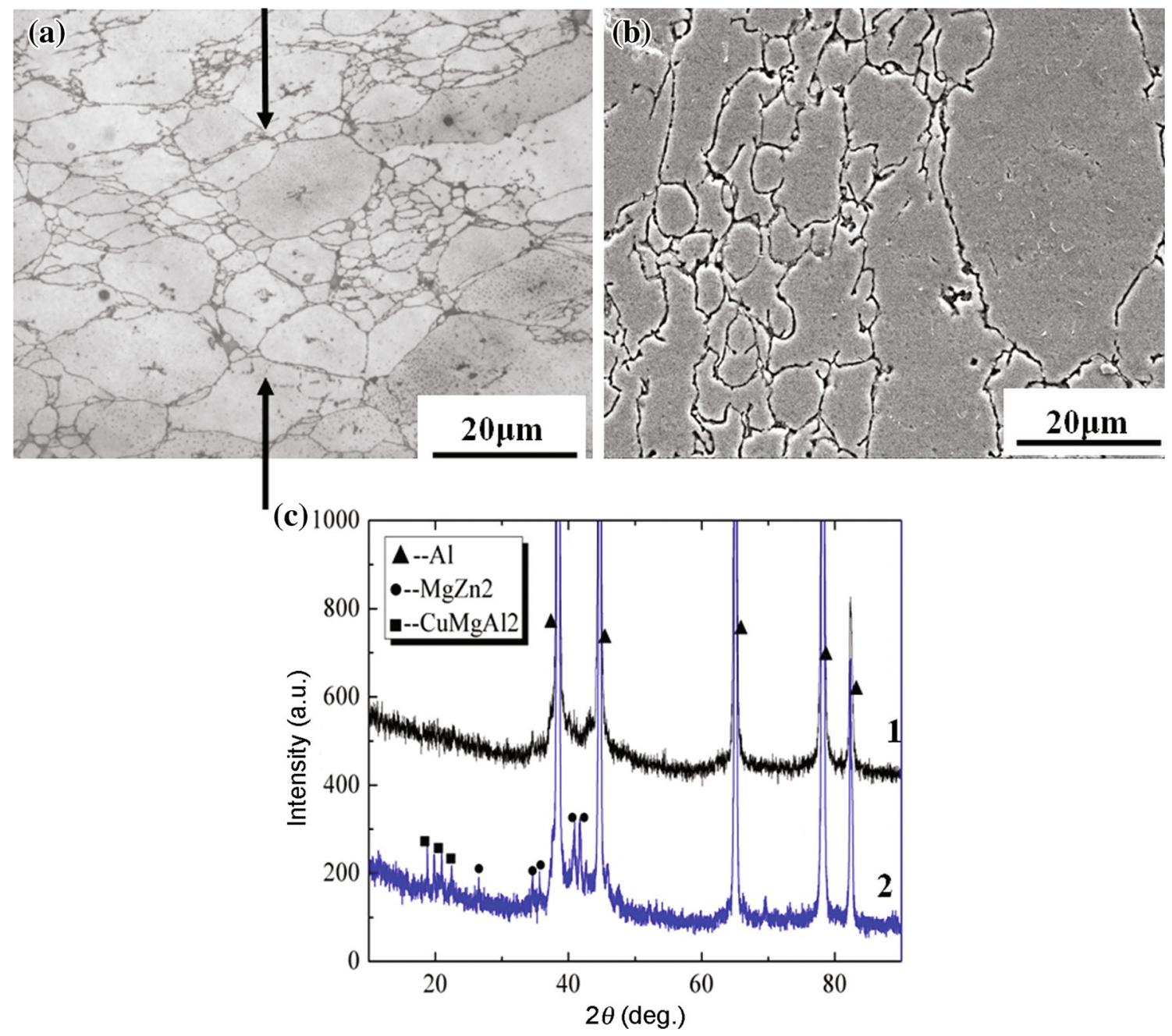

Fig. 14 Microstructure of the hot rolled strip: optical micrograph a, SEM image b, c represents the XRD patterns: hot rolled strip (1), semi-solid powder rolled strip (2). Arrows indicate the deformation axis 


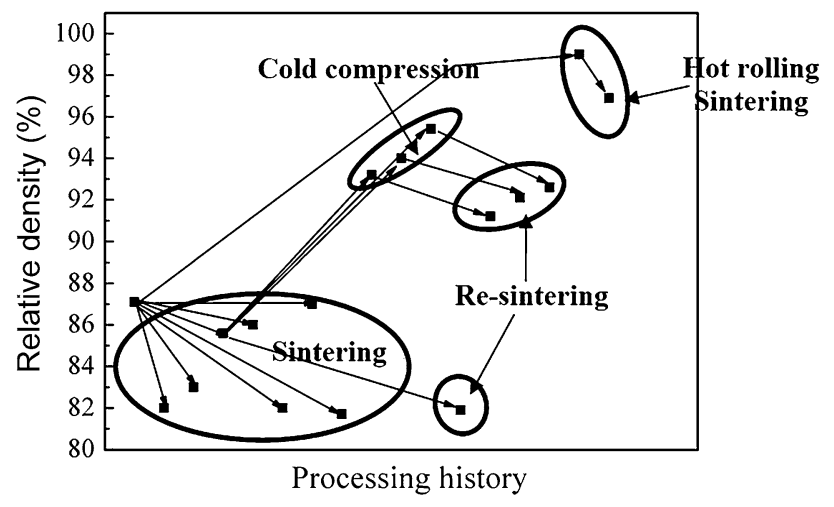

Fig. 15 Relative density of the processed alloy versus processing history

established that gas can be trapped in very fine pores where the internal pressure keeps the volume of gas to be very small. Therefore, re-sintering/extended annealing will allow the fine pores to coarsen leading to extensive swelling. So this again proves trapped gas swelling of pores.

Figure 15 summarizes the density change versus processing history. It can be seen that only deformation makes densification of the strips occur. Sintering process makes density decrease because trapped gas leads to the swelling of pores where the internal pressure keeps the volume of gas very small. No matter which kind of post-treatments used, microhardness increases compared with that of SSPR processed strips.

\section{Conclusions}

1. Semi-solid powder rolling (SSPR) is a novel strip manufacturing technology and 7050 aluminum alloy strips can be easily prepared. The semi-solid powder rolled strip prepared under a low liquid fraction $(<10 \%)$ using fine powders $(\leq 75 \mu \mathrm{m})$ with a relative density of $87.1 \%$ and microhardness of $92.3 \mathrm{HV}$ consists of some pores and shows a relatively low mechanical property. As a result, three post-treatment processes: sintering, "pre-sintering-cold deformation-sintering" and hot rolling, were discussed.

2. "Pre-sintering — cold deformation—sintering" and hot rolling are useful for the improvement in the density and microhardness. Even though sintering leads to the increase in microhardness, density decreases and pores grow larger. After "pre-sintering — cold deformationsintering" process, the maximum microhardness increases to $300 \mathrm{HV}$ and the highest relative density is $92.6 \%$. High microhardness is due to uniformly distributed secondary particles. The microhardness and relative density of hot rolled strip are $176 \mathrm{HV}$ and $99 \%$, respectively.
3. Both swelling of pores and densification occur during solid-state sintering of AA7050 alloy. The density decrease in the sintered specimens is due to that the effect of swelling of the pores on density change is larger than that of densification.

Acknowledgments This work was financially supported by the Fundamental Research Funds for the Central Universities and Science (No. 2011ZZ0010) and the Technology Innovation Project of Guangdong Provincial Department of Education (No. 2013KJCX0014).

\section{References}

[1] Y.Z. Liu, X. Luo, Z.L. Li, J. Mater. Proc. Technol. 214, 165 (2014)

[2] A. Heinz, A. Haszler, C. Keidel, S. Moldenhauer, R. Benedictus, W.S. Miller, Mater. Sci. Eng., A 280, 102 (2000)

[3] Z.Y. Chen, S.Q. Xu, X.H. Dong, Acta Metall. Sin. (Engl. Lett.) 27, 359 (2014)

[4] V. Kumar, I.V. Singh, B.K. Mishra, R. Jayaganthan, Acta Metall. Sin. (Engl. Lett.) 18, 211 (1997)

[5] W.Y. Jiang, T. Chen, L.P. Wang, Acta Metall. Sin. (Engl. Lett.) 26, 473 (2013)

[6] C.G. Kang, J.H. Yoon, Y.H. Seo, J. Mater. Proc. Technol. 66, 30 (1997)

[7] T. Varol, A. Canakci, S. Ozsahin, Acta Metall. Sin. (Engl. Lett.) 28, 182 (2015)

[8] W.G. Cho, C.G. Kang, J. Mater. Proc. Technol. 105, 269 (2000)

[9] M. Suery, M.C. Flemings, Metall. Trans. A 13, 1809 (1982)

[10] L.J. Zu, S.J. Luo, J. Mater. Proc. Technol. 114, 189 (2001)

[11] Y.F. Wu, G.Y. Kim, I.E. Anderson, J. Manufac. Sci. Eng. 132, 0110031 (2010)

[12] Y.F. Wu, G.Y. Kim, I.E. Anderson, Acta Mater. 58, 4398 (2010)

[13] Y.F. Wu, G.Y. Kim, Powder Technol. 214, 252 (2011)

[14] Y.F. Wu, G.Y. Kim, A.M. Russell, Mater. Sci. Eng. A 532, 558 (2012)

[15] Y.F. Wu, G.Y. Kim, A.M. Russell, Mater. Sci. Eng. A 538, 164 (2012)

[16] Y.F. Wu, Fabrication of Metal Matrix Composite by Semisolid Powder Processing, Ph.D. Dissertation, Iowa State University, 2011

[17] J.D. Robson, Mater. Sci. Eng. A 382, 112 (2004)

[18] R.D. Doherty, D.A. Hughes, F.J. Humphreys, Mater. Sci. Eng. A 238, 219 (1997)

[19] R. Imayev, E. Evangelista, O. Tassa, Mater. Sci. Eng. A 202, 128 (1995)

[20] H.V. Atkinson, D. Liu, Mater. Sci. Eng. A 496, 439 (2008)

[21] S.M. Lee, S.-J.L. Kang, Acta Mater 46, 3191 (1998)

[22] R.M. German, A. Bose, S.S. Mani, Metall. Trans. A 23, 211 (1992)

[23] N. Showaiter, M. Youseffi, Mater. Des. 29, 752 (2008)

[24] J. Pan, H.N. Chng, A.C.F. Cocks, Mech. Mater. 37, 705 (2005)

[25] G.B. Schaffer, B.J. Hall, Metall. Mater. Trans. A 33, 3279 (2002)

[26] R.F. Smart, E.C. Ellwood, Nature 181, 833 (1958)

[27] R.Q. Guo, P.K. Rohatgi, D. Nath, J. Mater. Sci. 32, 3971 (1997)

[28] Z.A. Munir, J. Mater. Sci. 14, 2733 (1979)

[29] Z.A. Munir, Powder Metall. 24, 177 (1981)

[30] P.K. Higgins, Z.A. Munir, Int. J. Powder Metall. 14, 26 (1982)

[31] M. Vlach, I. Stulikova, B. Smola, Mater. Sci. Eng. A 548, 27 (2012)

[32] S.K. Vajpai, R.K. Dube, S. Sangal, Mater. Sci. Eng. A 529, 378 (2011) 